\title{
Cognitive impairment is related to a reduced count of T-lymphocytes in older patients diagnosed with non-small cell lung cancer (NSCLC)
}

\author{
Teresa Soria-Comes ${ }^{1} \wedge$, Vicente Palomar-Abril ${ }^{2}$, María Martín Ureste ${ }^{1}$, Javier García Sánchez ${ }^{1}$, \\ Josefa Esperanza Marco Buades ${ }^{3}$, María José Fernández Llavador ${ }^{3}$, Amparo López Gabaldón ${ }^{3}$, \\ Mar González Jurado ${ }^{3}$, Inmaculada Concepción Maestu Maiques ${ }^{1 \wedge}$
}

${ }^{1}$ Department of Medical Oncology, Hospital Universitario Doctor Peset, Valencia, Comunitat Valenciana, Spain; ${ }^{2}$ Department of Medical Oncology, Hospital Virgen de los Lirios, Alicante, Comunitat Valenciana, Spain; ${ }^{3}$ Department of Hematology, Hospital Universitario Doctor Peset, Valencia, Comunitat Valenciana, Spain

Contributions: (I) Conception and design: T Soria-Comes, V Palomar-Abril, IC Maestu Maiques; (II) Administrative support: JE Marco Buades, MJ Fernández Llavador, A López Gabaldón, M González Jurado; (III) Provision of study materials or patients: T Soria-Comes, J García Sánchez, M Martín Ureste, V Palomar-Abril, JE Marco Buades, MJ Fernández Llavador, A López Gabaldón, M González Jurado; (IV) Collection and assembly of data: T Soria-Comes, V Palomar-Abril, J García Sánchez, M Martín Ureste, JE Marco Buades; (V) Data analysis and interpretation: Teresa SoriaComes, V Palomar-Abril, J García Sánchez, M Martín Ureste, IC Maestu Maiques; (VI) Manuscript writing: All authors; (VII) Final approval of manuscript: All authors.

Correspondence to: Teresa Soria-Comes, MD. Department of Medical Oncology, Hospital Universitario Doctor Peset, Valencia (46017), Comunitat Valenciana, Spain. Email: t.soria.comes@gmail.com.

Background: Aging is a risk factor for cancer and cognitive impairment, and both have been related to changes in the immune system (immunosenescence) and chronic inflammation (inflammaging) of elderly individuals. Therefore, it would be interesting to know if there is a connection between immunological variations and cognitive function in oncologic patients, especially in lung cancer, in which, inflammation plays a crucial role in tumor development and progression. Our objective is to assess, in older patients diagnosed with non-small cell lung cancer (NSCLC), differences in parameters of the immune system depending on their cognitive status.

Methods: We retrospectively analyzed patients $\geq 70$ years diagnosed with NSCLC with evaluated cognitive function, from January 2017 to April 2019. Lymphocyte count was gathered at baseline and checked for differences in lymphocyte counts between patients with a Pfeiffer result of 0-2 vs. 3-10 mistakes. Multiple regression models were used to assess the impact of clinical parameters on lymphocyte count.

Results: Seventy patients were analyzed. Sixty had a normal cognitive function, while ten had an impaired cognitive status; these were significantly older. Multivariate analysis showed that patients with cognitive impairment had lower levels of total, $\mathrm{T}$ and CD8+ T-lymphocytes ( $\mathrm{P}=0.011,0.011$ and 0.019, respectively). Older age was only correlated to higher level of CD8+ T-lymphocytes ( $\mathrm{P}=0.0390)$. Odds ratio for the risk of cognitive impairment depending on the level of T-lymphocytes was 0.996 (95\% CI: 0.995-0.998), P=0.037.

Conclusions: T-lymphocyte count is lower in patients diagnosed with lung cancer and cognitive impairment. These findings suggest that clinical features are closely related to immunological status in older patients with NSCLC. Therefore, age cannot always explain immunosenescence, and geriatric assessment could help.

Keywords: Immunosenescence; non-small cell lung cancer (NSCLC); comprehensive geriatric assessment; older patients; cognitive impairment

^ ORCID: Teresa Soria-Comes, 0000-0003-1125-7824; Vicente Palomar-Abril, 0000-0002-6753-7377; Inmaculada Concepción Maestu Maiques, 0000-0002-7901-0900. 
Submitted May 04, 2020. Accepted for publication Sep 18, 2020.

doi: $10.21037 /$ tcr-20-1997

View this article at: http://dx.doi.org/10.21037/tcr-20-1997

\section{Introduction}

Aging is a risk factor for both cancer and cognitive impairment $(1,2)$. Furthermore, cognitive alterations have been widely studied in patients diagnosed with neoplasms, specially related to treatment with chemotherapy, as a condition globally known as chemobrain or chemofog $(3,4)$. Despite this, the mechanisms that induce cognitive impairment in patients with cancer are not fully understood, especially in older patients, in which multiple risk factors coexist. Knowledge of associated factors to cognitive impairment in elderly patients with cancer appears to be of great importance given its higher prevalence in this population and the possible greater risk of treatments to induce or worsen cognitive damage (5).

During the last years, growing evidence of the relationship between immune alterations that occur with aging (known as immunosenescence) and neurodegenerative diseases has emerged $(6,7)$. The hallmarks of immunosenescence are reduced response to antigens and increased number of senescent cells associated with a chronic inflammatory status (inflammaging) (8) in a highly complex process that cannot only be explained by cellular aging, but is also influenced by antigenic exposure or nutritional status among other factors. Regarding neurodegenerative diseases, chronic systemic inflammation has demonstrated to alter the permeability of the bloodbrain barrier (BBB) and allow proinflammatory substances to cross the $\mathrm{BBB}$ and induce microglia activation and promotion of central nervous inflammation, that can cause brain damage $(6,7)$.

Immunosenescence has also been described as one of the main hallmarks of cancer: the immune system plays a major role in tumoral surveillance; but, due to a continuous stimulation by tumoral cells, it can also induce an inflammatory state and promote cancer growth (9). That is why, recently, there has been a great development of treatments that enhance immune cells to destroy tumour cells. This is especially important in non-small cell lung cancer (NSCLC) given its relationship with inflammation and tumor development and progression (10). Furthermore, median age of diagnosis of NSCLC is around 70 years (11); that implies a higher number of patients in daily clinical practice that, because of their age, are more prone to suffer from cognitive diseases.

Although there is a reasonable connection between brain damage, cancer development and immunosenescence; risk factors that promote cognitive impairment related to cancer in older patients and biological markers linked to immunosenescence are yet unknown. For this reason, the objective of this study is to assess, in older people diagnosed with NSCLC, if there is a statistically significant difference in lymphocyte populations depending on their cognitive status defined by the screening Pfeiffer test. We present the following article in accordance with the STROBE reporting checklist (available at http://dx.doi.org/10.21037/tcr-201997).

\section{Methods}

\section{Study design}

We performed a cross-sectional study including patients of $\geq 70$ years diagnosed with NSCLC from January 2017 to April 2019 at Hospital Universitario Doctor Peset (Valencia, Spain). Clinical staging was defined according to the guidelines of the tumor-node-metastasis (TNM) staging system of the Union for International Cancer Control (8th Edition) (12).

Patients older than 70 years with a histopathological diagnosis of NSCLC were incorporated into the study if their analytical and clinical profiling information was available, together with the comprehensive geriatric assessment that includes the evaluation of the performance of daily living activities and instrumental daily living activities, cognitive, nutritional and emotional status, and comorbidities. Among the cases reviewed, only patients who had undergone the Pfeiffer test were considered eligible, while those previously diagnosed with an immunodeficiency, an autoimmune disease or a chronic infection (such as HIV or hepatitis) were considered ineligible. The demographic and clinicopathologic characteristics were recorded and archived in the hospital informatics system. The study was conducted in accordance with the Declaration of Helsinki (as revised in 2013) and it was approved by the Ethics Committee of the Hospital Universitario Doctor Peset (ID 
Table 1 Short portable mental status questionnaire (SPMSQ) or Pfeiffer screening test

1. What are the date, month and year?

2. What is the day of the week?

3. What is the name of this place?

4. What is your phone number?

5. How old are you?

6. When were you born?

7. Who is the current president?

8. Who was the president before him/her?

9. What is your mother's surname?

10. Can you count backward from 20 by 3's?

local code 77/17). Written informed consent was exempted because of the retrospective nature of the study and assured anonymity.

\section{Blood samples and lymphocyte count}

During the first appointment in the Medical Oncology clinic, blood samples were obtained aseptically by venipuncture and collected in EDTA tubes to assess the lymphocyte profile during the following 2-4 hours after collection. The blood samples in the present study were collected between 9:00 and 11:00 am, in order to minimize the possible effects of circadian rhythmicity shown by certain immune cells. Lymphocyte count by flow cytometry was gathered from this blood test at baseline. Immunophenotyping included $\mathrm{CD}^{+}, \mathrm{CD}^{+}{ }^{+}$and $\mathrm{CD} 8^{+}$ T-lymphocytes, B-lymphocytes and natural killer (NK)lymphocytes. The analysis was performed in the cytometry laboratory at the Hematology Department of our hospital using a Beckman Coulter ${ }^{\circledR}$ flow cytometer and the data were reported in absolute and relative values. Moreover, the rest of hematologic and biochemistry parameters were gathered. Flow cytometry is a widely used technique, available in most hospitals, which makes it the ideal procedure to evaluate immune system in daily clinical practice.

\section{Pfeiffer test}

During the first visit in the Medical Oncology clinic a complete medical interview is performed, usually including the geriatric assessment in older patients. Comprehensive geriatric assessment includes evaluation of cognitive status using the short portable mental status questionnaire (SPMSQ) or Pfeiffer test in the patient's mother tongue, as recommended by the Working Group on Oncogeriatrics of the Spanish Society of Medical Oncology (13). This is a validated and reproducible tool to evaluate cognitive status in older patients, composed of 10 items listed in Table 1 (14). Each question that is not answered correctly counts as one mistake (range of $0-10$ mistakes). The cutoff point to establish a significant cognitive impairment is set at more than 2 mistakes, since in our cohort, older patients could read and write.

\section{Statistical analysis}

Frequency tabulation and summary statistics are listed to characterize the data distributions. Also, we studied if there were statistically significant differences in blood cell counts and, more specifically, in populations of lymphocyte counts between the older patients with a Pfeiffer result of 0-2 mistakes (not significantly impaired) vs. 3-10 mistakes (impaired). The Kolmogorov-Smirnov test was used for the distribution test. The non-parametric Mann-Whitney $\mathrm{U}$ test was used to assess differences in lymphocyte subpopulation counts between patients with a significantly diminished cognitive function and a normal cognitive status. Multiple regression models were used to assess the impact of clinical parameters on lymphocyte count. A difference with $\mathrm{P}$ value of less than 0.05 was considered to be statistically significant.

\section{Results}

\section{Patients}

Seventy patients were analyzed in the study. The demographic characteristics of the patients, the tumor type, clinical stage and classification based on the result of the Pfeiffer test are summarized in Table 2. Patients ranged in age from 70 to 90 years. Median age was significantly higher in the group with cognitive impairment (80 vs. 76 years; $\mathrm{P}=0.0257$ ), and this was considered in the subsequent multivariate analysis. In our cohort, $14.3 \%$ were female and most patients had a former or current history of a smoking habit $(81.4 \%)$. The performance status was $0-1$ in $75.8 \%$ of patients. Among all the patients analyzed, $85.7 \%[60 / 70]$ were considered to have a normal cognitive function, and $14.3 \%$ [10/70], an impaired cognitive status. 
Table 2 Demographics and clinical characteristics of older patients diagnosed with non-small cell lung cancer (NSCLC)

\begin{tabular}{|c|c|}
\hline Variable & Patients $(n=70)$ \\
\hline Age (years), median [range] & 77 [70-90] \\
\hline \multicolumn{2}{|l|}{ Sex, n (\%) } \\
\hline Male & $60(85.7)$ \\
\hline Female & $10(14.3)$ \\
\hline \multicolumn{2}{|l|}{ Smoking status, n (\%) } \\
\hline Non-smoker & $6(8.6)$ \\
\hline Current smoker & $10(14.3)$ \\
\hline Ex-smoker & $54(77.1)$ \\
\hline \multicolumn{2}{|l|}{ ECOG PS score, n (\%) } \\
\hline 0 & $23(32.9)$ \\
\hline 1 & $30(42.9)$ \\
\hline 2 & $13(18.6)$ \\
\hline 3 & $4(5.7)$ \\
\hline \multicolumn{2}{|l|}{ Histology, n (\%) } \\
\hline Adenocarcinoma & $35(50.0)$ \\
\hline Squamous carcinoma & $30(42.9)$ \\
\hline Other & $5(7.1)$ \\
\hline \multicolumn{2}{|l|}{ Clinical stage, $n(\%)$} \\
\hline 1 & $6(8.7)$ \\
\hline II & $10(14.5)$ \\
\hline III & $31(44.9)$ \\
\hline IV & $22(31.9)$ \\
\hline \multicolumn{2}{|l|}{ Pfeiffer test, $\mathrm{n}(\%)$} \\
\hline Normal (0-2 mistakes) & $60(85.7)$ \\
\hline Significantly impaired (3-10 mistakes) & $10(14.3)$ \\
\hline
\end{tabular}

Among patients with cognitive impairment, $80 \%$ were male $[8 / 10]$.

In the general blood cell count, only lymphocyte count was significantly different between the two groups: patients with cognitive impairment had lower levels of lymphocytes (median lymphocyte count 1,200 vs. $1,500, \mathrm{P}=0.0328$, data shown in Table 3 and Figure 1). Table 3 also shows the median lymphocyte count and the interquartile range depending on the cognitive status of the patients included in the analysis.

\section{Relationship between NK lymphocytes and cognitive status}

Regarding the innate immunity, the median value of NK lymphocyte was similar between the two groups: in patients with a significantly impaired cognitive function the median value was $268 v s .271$ cells $/ \mathrm{mm}^{3}$ in the group of not impaired cognitive status $(\mathrm{P}=0.4513)$.

\section{Relationship between T lymphocytes and cognitive status}

Next, the subpopulation of $T$ lymphocytes was analyzed: the median value of the total T-lymphocyte count was significantly lower in the group considered to have cognitive impairment, 882 cells $/ \mathrm{mm}^{3}$ (impaired) vs. 1,027 cells $/ \mathrm{mm}^{3}$ (not impaired) $(\mathrm{P}=0.0490)$ (Figure 1). However, no differences were observed for the for $\mathrm{CD} 4^{+} \mathrm{T}$ lymphocytes (504 vs. 556 cells $/ \mathrm{mm}^{3}, \mathrm{P}=0.0948$ ) and for $\mathrm{CD}^{+} \mathrm{T}$ lymphocytes (341 vs. 404 cells $/ \mathrm{mm}^{3}, \mathrm{P}=0.1091$ ).

\section{Relationship between B lymphocytes and cognitive status}

In the subset of B-lymphocyte population, the median value showed to be statistically lower in the cohort with impaired cognitive status ( 41 vs. 74 cells $/ \mathrm{mm}^{3}, \mathrm{P}=0.0146$ ). Significant differences between cell-count levels according to cognitive status are also shown in Figure 1.

\section{Multivariate analysis}

With these results, we performed the multivariate analysis using multiple regression models, taking into consideration, not only cognitive status, but also age, nutritional condition and tumoral stage. To assess nutritional status body mass index (BMI) and serum levels of albumin were considered. As shown in Table 4, cognitive status (not impaired $v$ s. impaired) was an independent factor related to total lymphocyte levels, T-lymphocyte count and, specifically $\mathrm{CD}^{+} \mathrm{T}$ lymphocytes. The coefficient obtained was negative in all three cases, showing that patients with an impaired cognitive function had significantly lower levels of these cell subsets. Interestingly, age was only positively correlated to the level of $\mathrm{CD} 8^{+} \mathrm{T}$ lymphocytes (Table 4).

Subsequently, a multiple logistic regression analysis was performed, including age and the main lymphocyte subsets (B-lymphocytes, T-lymphocytes and NKlymphocytes). The logistic regression analysis revealed 
Table 3 Median and interquartile range of cell count in peripheral blood samples from older patients based on their results of the SPMSQ

\begin{tabular}{lccc}
\hline Parameters & Normal Pfeiffer test $(\mathrm{n}=60)$ & Altered Pfeiffer test $(\mathrm{n}=10)$ & $\mathrm{P}$ value \\
\hline Hemoglobin $(\mathrm{g} / \mathrm{dL})$ & $12.9[11.9-14.4]$ & $12.8[12.3-13.8]$ & 0.7096 \\
Platelets $\left(10^{3}\right.$ cells $\left./ \mathrm{mm}^{3}\right)$ & $232[197-292]$ & $228[188-297]$ & 0.5854 \\
Neutrophils $\left(\mathrm{cells} / \mathrm{mm}^{3}\right)$ & $5,650[4,200-7,200]$ & $5,850[5,300-7,500]$ & 0.4616 \\
Lymphocytes $\left(\mathrm{cells} / \mathrm{mm}^{3}\right)$ & $1,500[1,100-2,300]$ & $1,200[600-1,400]$ & 0.0328 \\
NK-lymphocyte count $\left(\mathrm{cells} / \mathrm{mm}^{3}\right)$ & $271[204-461]$ & $268[94-347]$ & 0.4513 \\
T-lymphocyte count $\left(\mathrm{CD}^{+}\right)\left(\mathrm{cells} / \mathrm{mm}^{3}\right)$ & $1,027[762-1,580]$ & $882[457-938]$ & 0.0490 \\
CD4 & $504[297-591]$ & 0.0948 \\
CD8 ${ }^{+}$T-lymphocyte count $\left(\mathrm{cells} / \mathrm{mm}^{3}\right)$ & $556[423-776]$ & $341[270-450]$ & 0.1091 \\
B-lymphocyte count $\left(\mathrm{cells} / \mathrm{mm}^{3}\right)$ & $404[267-646]$ & $41[17-67]$ & 0.0146 \\
\hline
\end{tabular}

SPMSQ, short portable mental status questionnaire; also, Pfeiffer test; NK, natural killer.

that age was significantly associated with a higher risk of cognitive impairment [odds ratio (OR) 1.1969 (95\% CI: $1.022-1.400), \mathrm{P}=0.0254]$; and higher levels of T-lymphocytes were associated with a lower risk of cognitive impairment [OR 0.996 (95\% CI: 0.995-0.998), P=0.037]. Levels of B-lymphocytes and NK-lymphocytes showed no significant association with cognitive impairment.

\section{Discussion}

In this study we analyzed blood count parameters in patients older than 70 years diagnosed with NSCLC, who had been tested for cognitive dysfunction with the SPMSQ, and our results show that cognitive impairment is significantly associated with a lower lymphocyte count, and specifically reduced total and CD ${ }^{+}$T-lymphocyte levels. To our knowledge, this is the first study that demonstrates a significant correlation between immunological status and cognitive function in patients with cancer.

It is known that cognitive impairment is more prevalent in aged individuals (15), and older age is also a risk factor for cancer development; and these are two of the conditions related to immunological shifts in the elderly. That is why, at this point, it is essential to outline the main changes that occur in the immune system during aging, in a process that is denominated immunosenescence. As described previously, immunosenescence is characterized by a reduced response capacity to new antigens and increased number of memory and senescent cells associated with low grade of chronic inflammation, known as inflammaging $(8,9)$. This changes have been deeply investigated regarding the distribution of $\mathrm{T}$ cell subpopulations: in elderly healthy people, naïve
T-lymphocytes decrease $\left(\mathrm{CD} 8^{+} \mathrm{CD} 28^{+} \mathrm{CD} 45 \mathrm{RA}^{+}\right)$and highly mature terminally differentiated cells increase $\left(\mathrm{CD}^{+} \mathrm{CD} 28^{-} \mathrm{CD} 45 \mathrm{RA}^{+}\right)(16,17)$. However, to study these subpopulations would imply using more specific antibodies that are not currently used in clinical practice and that surpass the objective of this investigation. Interestingly, results regarding total $\mathrm{CD}^{+}$and $\mathrm{CD}^{+}$lymphocytes have been conflicting in old healthy individuals, and higher and lower $\mathrm{CD}^{+}$total lymphocyte counts have been reported in healthy older individuals $(18,19)$. Moreover, changes in the B-lymphocyte population $\left(\mathrm{CD} 19^{+}\right)$have been described, and a decrease in their total number has been observed. Also, NK lymphocytes have been examined with a high interest because of its part in tumour cell destruction. During normal aging, the function of these cells reduces, but this is balanced because the number of these cells increases (20). Although classically these changes were associated with a loss of functionality, their impact is still not completely understood and even to a lesser extent in patients with cancer.

Our findings support the results of the publication by Magaki et al. (21), including older patients with and without cognitive impairment. In this study, patients diagnosed with mild cognitive impairment had a significantly lower level of total lymphocytes and higher level of neutrophils. However, they were not able to find differences among lymphocyte subsets. The evidence of differential lymphocyte levels according to cognitive status, is also sustained by several studies that have correlated higher levels of neutrophil to lymphocyte ratio (NLR) to cognitive impairment $(22,23)$. Although there is scarce data about specific lymphocyte subsets in patients with 


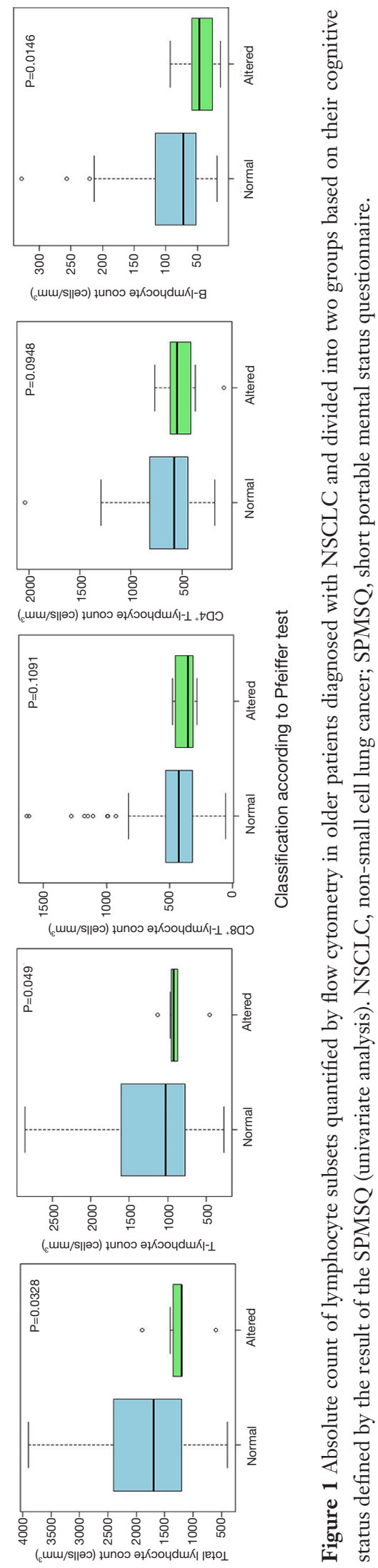

cognitive impairment, there is increasing evidence of the relationship between inflammatory status and cognition $(24,25)$. Mechanisms by which cognitive impairment is related to inflammatory status are not fully understood, nevertheless, systemic inflammation could induce a similar level of central nervous system inflammatory status mediated by different mechanisms, including activation of peripheral nerves (26) and increased permeabilization of the $\mathrm{BBB}$, both inducing the production of proinflammatory cytokines by the microglia and astrocytes. Inflammation at this level would alter brain structures and could be associated with functional declining (27). Nonetheless, the connection between cognitive impairment and the level of T lymphocytes is harder to elucidate. Older patients in our study with cognitive impairment had significant lower levels of total, $\mathrm{T}$ and $\mathrm{CD} 8^{+}$lymphocytes compared to elders with normal cognitive functioning, regardless of chronological age, which could indicate more extensive changes related to immunosenescence (17), or even sequestration of $\mathrm{CD} 8^{+}$T-lymphocytes in the central nervous system as postulated by Richartz-Salzburger et al. (28) in a study including patients with Alzheimer disease with a similar lymphocyte distribution to the one reported in our analysis. Nevertheless, although a higher risk of cognitive impairment was also found in patients with lower levels of T-lymphocytes, due to the cross-sectional design of our study, no causal correlations could be stablished. On the other hand, in old healthy people, it has been observed that naïve T-lymphocytes decrease in number (mainly among the $\mathrm{CD} 8^{+}$subpopulation) and highly mature terminally differentiated cells increase in number $(16,29)$, including an increased number of autoreactive $T$ lymphocytes that lead to higher levels of proinflammatory markers [such as IL-6 and C-reactive protein (CRP)] and participating in neural degeneration (30). That is why, lymphocyte distribution and differentiation and their correlation with cognitive impairment is being investigated including larger and prospective cohorts of patients diagnosed with lung cancer.

The rationale of exploring the relationship between immunological and cognitive status of patients diagnosed with lung cancer is considerable: firstly, during the last few years there has been a great development in Oncology of new drugs that work enhancing the immune system to fight against the tumor. This is especially interesting in advanced lung cancer, because it is known that it is a tumor with an important inflammatory component, and many immunotherapy agents used in the clinical practice are directed to this neoplasm $(31,32)$. That is why it is 
Table 4 Multivariate analysis including clinical parameters that could be related to lymphocyte counts in older patients with lung cancer (age, Pfeiffer test result, BMI, albumin and tumoral stage)

\begin{tabular}{|c|c|c|c|c|c|}
\hline Parameters & $\begin{array}{l}\text { Coefficient for total } \\
\text { lymphocytes }(95 \% \mathrm{Cl}) \text {, } \\
\mathrm{P} \text { value }\end{array}$ & $\begin{array}{l}\text { Coefficient for } T \\
\text { lymphocytes }(95 \% \mathrm{Cl}) \text {, } \\
P \text { value }\end{array}$ & $\begin{array}{l}\text { Coefficient for } \mathrm{CD} 8^{+} \mathrm{T} \\
\text { lymphocytes }(95 \% \mathrm{Cl}) \text {, } \\
\mathrm{P} \text { value }\end{array}$ & $\begin{array}{l}\text { Coefficient for } \mathrm{CD} 4^{+} \mathrm{T} \\
\text { lymphocytes }(95 \% \mathrm{Cl}) \text {, } \\
\mathrm{P} \text { value }\end{array}$ & $\begin{array}{l}\text { Coefficient for } \\
\text { B lymphocytes } \\
(95 \% \text { Cl), P value }\end{array}$ \\
\hline $\begin{array}{l}\text { Pfeiffer test } \\
\text { (normal vs. } \\
\text { impaired) }\end{array}$ & $\begin{array}{l}-724.25(-1,276.08 \text { to } \\
-172.42), 0.0110\end{array}$ & $\begin{array}{l}-507.55(-896.05 \text { to } \\
-11.06), 0.0113\end{array}$ & $\begin{array}{l}-310.74(-568.70 \text { to } \\
-52.82), 0.0190\end{array}$ & $\begin{array}{l}-210.84(-443.86 \text { to } \\
22.17), 0.0753\end{array}$ & $\begin{array}{l}-43.00(-87.00 \text { to } \\
0.92), 0.0548\end{array}$ \\
\hline BMI $\left(\mathrm{kg} / \mathrm{m}^{2}\right)$ & $\begin{array}{l}-7.16 \text { (-54.73 to } 49.42) \\
0.7645\end{array}$ & $\begin{array}{l}-2.91(-35.24 \text { to } 30.40) \\
0.8616\end{array}$ & $\begin{array}{l}-9.71(-31.83 \text { to } 12.41) \\
0.3833\end{array}$ & $\begin{array}{l}3.96(-16.027 \text { to } 23.95) \\
0.6932\end{array}$ & $\begin{array}{l}-2.25(-6.02 \text { to } \\
1.42), 0.2386\end{array}$ \\
\hline Albumin (g/dL) & $\begin{array}{l}-128.55(-657.67 \text { to } \\
400.58), 0.6287\end{array}$ & $\begin{array}{l}-69.65(-440.01 \text { to } \\
300.72), 0.7081\end{array}$ & $\begin{array}{l}-86.30(-332.19 \text { to } \\
159.58), 0.4853\end{array}$ & $\begin{array}{l}11.91(-210.24 \text { to } \\
234.05), 0.9150\end{array}$ & $\begin{array}{l}-8.27(-50.10 \text { to } \\
33.56), 0.6939\end{array}$ \\
\hline
\end{tabular}

BMI, body mass index.

essential to study the variations in the immune system in these patients and other clinical parameters that could influence immunological modulation during aging, such as cognitive impairment (21). Secondly, cancer-related cognitive impairment is a widely recognized entity, initially related to chemotherapy (33), radiation therapy and hormonal therapy (34), but that has proved to be present in patients before initiating any treatment and in patients after cancer surgery (35). The process by which cancer itself can induce cognitive impairment involves humoral responses, especially in lung cancer patients (36), and increased level of circulating proinflammatory cytokines related to lymphocyte repertoire (37). As all the patients included in our study had been diagnosed with NSCLC, we hypothesized that advanced tumoral stage might also influence immunological status, as reported in a study by Onyema et al. (38); however, we found no significant differences in lymphocyte populations depending on the extent of the disease. This differences could be due to the differences in the population included in their study, in which patients with small cell lung cancer and mesothelioma were also included, with a relatively low sample size ( $\mathrm{n}=24$ patients); but these disease's characteristics and evolution significantly differ from NSCLC and this could have acted as a confounding factor for the variation among lymphocyte subsets and should be investigated.

Moreover, besides aging, another crucial prognostic factor in lung cancer, that has also been related to immune modulation during aging is nutritional status (39-41).
Although BMI is a classical clinical parameter to evaluate nutritional condition, it has been demonstrated insufficient in patients diagnosed with cancer, as obese patients might also present with malnutrition $(42,43)$, which is why, albumin was also included in multivariate analysis $(44,45)$. Despite the data on previous publications, in our cohort, these nutritional parameters did not correlate to immunological status.

The limitations of our study include a relatively low sample size and its basis in a single center experience, which might have led to a lack of statistical power to detect differences in other lymphocyte subpopulations. Furthermore, not all the older patients diagnosed with NSCLC during the period of our analysis had been tested for their cognitive status until the comprehensive geriatric assessment was included in the diagnostic protocol of patients aged 70 years or more diagnosed with cancer in our Department, which explains the small size of the population analyzed. Also, although trends in lung cancer incidence have varied since the last few years, it is still a more prevalent disease in men (46); and consequently, there was a low percentage of female population eligible for our analysis. This, added to the relatively reduced sample size, is why potential gender differences could not be assessed. However, this fact is not considered a major issue because although Alzheimer disease is more prevalent in women, mild cognitive impairment incidence is similar in both sexes (47). Additionally, the most significant changes described in the immune system of older people are 
mainly described in subsets of $\mathrm{CD} 8^{+} \mathrm{T}$ lymphocytes that have different functionality (divided into naïve, central memory, effector memory and terminally differentiated effector memory cells using surface markers) (16). Although variations in the immune system could not only be related to aging, but also to clinical impairment, we did not perform these determinations, because this surpass the scope of this study and warrants further exploration. On the other hand, one of the strengths of our study is that the only major exclusion criteria are suffering from an autoimmune or a chronic infectious disease, resulting in a highly heterogeneous sample that is similar to the patients we encounter in clinical practice. Furthermore, despite the reduced number of patients diagnosed with cognitive impairment, statistically differences were found, and these results make our investigation a relevant hypothesis generating study. Finally, the use of a widely extended technique as flow cytometry, which is available in most hospitals, allows for applying these determinations in routine clinical practice.

Taken together, our results suggest that immune changes in older patients diagnosed with NSCLC are connected not only to age, but also to clinical parameters. The comprehensive geriatric assessment is a widely recognized tool to evaluate older patients with cancer and encompasses many different areas of human functioning. It has been proved that chronological age is not sufficient to characterize the heterogeneity of the older people diagnosed with cancer (48) and it is crucial to identify a subset of patients that can have reduced life expectancy and possibly a different expected benefit and toxicity of new treatments such as immunotherapy. That is why it is of particular interest to further study the possible relationship between the immunological status and functional, environmental or cognitive situation. Specifically, understanding risk factors for cognitive disfunction and the interaction between cancer treatment and the aging process would help oncologists to weigh the potential benefits and risks of therapy, and guide treatment decision making.

In conclusion, immunosenescence is a widely recognized phenomenon in general population, mainly related to aging. Nonetheless, the impact of functional, cognitive, or nutritional status especially in oncologic patients has not been deeply assessed yet. Our data show that cognitive impairment is related to a lower count of lymphocytes, and specifically of T-lymphocyte and $\mathrm{CD} 8^{+}$subsets. These findings suggest that clinical parameters are closely correlated to immunological status in older patients diagnosed with NSCLC. However, this needs further investigation, and this is why we are performing studies regarding clinical parameters of geriatric assessment including larger cohorts and deeper analysis of lymphocyte differentiation.

\section{Highlights}

(I) Immunosenescence refers to the changes that occur in the immune system during aging;

(II) Cognitive dysfunction is associated with changes in immune system in cancer patients;

(III) Low T-cell count is seen in cancer patients with cognitive impairment besides age;

(IV) Age cannot always explain immunosenescence, geriatric assessment could help.

\section{Acknowledgments}

The authors would like to express our gratitude to Joanna Gołab for her contribution preparing the manuscript. Funding: None.

\section{Footnote}

Reporting Checklist: The authors have completed the STROBE reporting checklist. Available at http://dx.doi. org/10.21037/tcr-20-1997

Data Sharing Statement: Available at http://dx.doi. org/10.21037/tcr-20-1997

Peer Review File: Available at http://dx.doi.org/10.21037/tcr20-1997

Conflicts of Interest: All authors have completed the ICMJE uniform disclosure form (available at http://dx.doi. org/10.21037/tcr-20-1997). The authors have no conflicts of interest to declare.

Ethical Statement: The authors are accountable for all aspects of the work in ensuring that questions related to the accuracy or integrity of any part of the work are appropriately investigated and resolved. The study was conducted in accordance with the Declaration of Helsinki (as revised in 2013) and it was approved by the Ethics Committee of the Hospital Universitario Doctor Peset (ID local code 77/17). Written informed consent was exempted 
because of the retrospective nature of the study and assured anonymity.

Open Access Statement: This is an Open Access article distributed in accordance with the Creative Commons Attribution-NonCommercial-NoDerivs 4.0 International License (CC BY-NC-ND 4.0), which permits the noncommercial replication and distribution of the article with the strict proviso that no changes or edits are made and the original work is properly cited (including links to both the formal publication through the relevant DOI and the license). See: https://creativecommons.org/licenses/by-nc-nd/4.0/.

\section{References}

1. Tangalos EG, Petersen RC. Mild Cognitive Impairment in Geriatrics. Clin Geriatr Med 2018;34:563-89.

2. Li D, de Glas NA, Hurria A. Cancer and Aging: General Principles, Biology, and Geriatric Assessment. Clin Geriatr Med 2016;32:1-15.

3. Ongnok B, Chattipakorn N, Chattipakorn SC. Doxorubicin and cisplatin induced cognitive impairment: The possible mechanisms and interventions. Exp Neurol 2020;324:113118.

4. Ren X, St Clair DK, Butterfield DA. Dysregulation of cytokine mediated chemotherapy induced cognitive impairment. Pharmacol Res 2017;117:267-73.

5. Cerulla Torrente N, Navarro Pastor JB, de la Osa Chaparro N. Systematic review of cognitive sequelae of non-central nervous system cancer and cancer therapy. J Cancer Surviv 2020;14:464-82.

6. Fülöp T, Dupuis G, Witkowski JM, et al. The role of immunosenescence in the development of age-related diseases. Rev Invest Clin 2016;68:84-91

7. Martorana A, Bulati M, Buffa S, et al. Immunosenescence, inflammation and Alzheimer's disease. Longev Healthspan 2012;1:8.

8. Pawelec G. Hallmarks of human "immunosenescence": adaptation or dysregulation? Immun Ageing 2012;9:15.

9. Fülöp T, Montgomery RR. Editorial overview: Immune senescence: known knowns and unknown unknowns. Curr Opin Immunol 2014;29:vii-ix.

10. Saavedra D, García B, Lorenzo-Luaces P, et al. Biomarkers related to immunosenescence: relationships with therapy and survival in lung cancer patients. Cancer Immunol Immunother 2016;65:37-45.

11. Owonikoko TK, Ragin CC, Belani CP, et al. Lung cancer in elderly patients: An analysis of the surveillance, epidemiology, and end results database. J Clin Oncol 2007;25:5570-7.

12. Goldstraw P, Chansky K, Crowley J, et al. The IASLC lung cancer staging project: Proposals for revision of the TNM stage groupings in the forthcoming (eighth) edition of the TNM Classification for lung cancer. J Thorac Oncol 2016;11:39-51.

13. Molina-Garrido MJ, Guillén-Ponce C, Blanco R, et al. Delphi consensus of an expert committee in oncogeriatrics regarding comprehensive geriatric assessment in seniors with cancer in Spain. J Geriatr Oncol 2018;9:337-45.

14. Pfeiffer E. A Short Portable Mental Status Questionnaire for the Assessment of Organic Brain Deficit in Elderly Patients. J Am Geriatr Soc 1975;23:433-41.

15. Gillis C, Mirzaei F, Potashman M, et al. The incidence of mild cognitive impairment: A systematic review and data synthesis. Alzheimers Dement (Amst) 2019;11:248-56.

16. Larbi A, Fulop T. From "truly naïve" to "exhausted senescent" T cells: when markers predict functionality. Cytometry A 2014;85:25-35.

17. Saavedra D, Garcia B, Lage A. T Cell Subpopulations in Healthy Elderly and Lung Cancer Patients: Insights from Cuban Studies. Front Immunol 2017;8:146.

18. Utsuyama M, Kikuchi Y, Kitagawa M, et al. Agerelated Changes in Subpopulations of Peripheral Blood Lymphocytes in Healthy Japanese Population. In: Fulop T, Franceschi C, Hirokawa K, et al. editors. Handbook on Immunosenescence. Dordrecht: Springer, 2009:203-18.

19. Alam I, Goldeck D, Larbi A, et al. Aging affects the proportions of $\mathrm{T}$ and $\mathrm{B}$ cells in a group of elderly men in a developing country-a pilot study from Pakistan. Age (Dordr) 2013;35:1521-30.

20. Gayoso I, Sanchez-Correa B, Campos C, et al. Immunosenescence of human natural killer cells. J Innate Immun 2011;3:337-43.

21. Magaki S, Yellon SM, Mueller C, et al. Immunophenotypes in the circulation of patients with mild cognitive impairment. J Psychiatr Res 2008;42:240-6.

22. Kuyumcu ME, Yesil Y, Oztürk ZA, et al. The evaluation of neutrophil-lymphocyte ratio in Alzheimer's disease. Dement Geriatr Cogn Disord 2012;34:69-74.

23. An P, Zhou X, Du Y, et al. Association of NeutrophilLymphocyte Ratio with Mild Cognitive Impairment in Elderly Chinese Adults: A Case-control Study. Curr Alzheimer Res 2019;16:1309-15.

24. 'Tegeler C, O’Sullivan JL, Bucholtz N, et al. The inflammatory markers CRP, IL-6, and IL-10 are associated with cognitive function-data from the Berlin Aging Study 
II. Neurobiol Aging 2016;38:112-7.

25. Lin T, Liu GA, Perez E, et al. Systemic Inflammation Mediates Age-Related Cognitive Deficits. Front Aging Neurosci 2018;10:236.

26. McCusker RH, Kelley KW. Immune-neural connections: How the immune system's response to infectious agents influences behavior. J Exp Biol 2013;216:84-98

27. Varatharaj A, Galea I. The blood-brain barrier in systemic inflammation. Brain Behav Immun 2017;60:1-12

28. Richartz-Salzburger E, Batra A, Stransky E, et al. Altered lymphocyte distribution in Alzheimer's disease. J Psychiatr Res 2007;41:174-8.

29. Qi Q, Zhang DW, Weyand CM, et al. Mechanisms shaping the naïve $\mathrm{T}$ cell repertoire in the elderly - thymic involution or peripheral homeostatic proliferation? Exp Gerontol 2014;54:71-4.

30. Liang Z, Zhao Y, Ruan L, et al. Impact of aging immune system on neurodegeneration and potential immunotherapies. Prog Neurobiol 2017;157:2-28.

31. Antonia SJ, Villegas A, Daniel D, et al. Durvalumab after Chemoradiotherapy in Stage III Non-Small-Cell Lung Cancer. N Engl J Med 2017;377:1919-29.

32. Sgambato A, Casaluce F, Gridelli C. The role of checkpoint inhibitors immunotherapy in advanced nonsmall cell lung cancer in the elderly. Expert Opin Biol Ther 2017;17:565-71.

33. van der Willik KD, Koppelmans V, Hauptmann M, et al. Inflammation markers and cognitive performance in breast cancer survivors 20 years after completion of chemotherapy: a cohort study. Breast Cancer Res 2018;20:135.

34. Lange M, Joly F, Vardy J, et al. Cancer-related cognitive impairment: An update on state of the art, detection, and management strategies in cancer survivors. Ann Oncol 2019;30:1925-40.

35. Lu XY, Chen M, Chen DH, et al. Remifentanil on T lymphocytes, cognitive function and inflammatory cytokines of patients undergoing radical surgery for cervical cancer. Eur Rev Med Pharmacol Sci 2018;22:2854-9.

36. Rybacka-Mossakowska J, Ramlau R, Gazdulska J, et al. Humoral Immune Response against Neural Antigens and Its Effects on Cognition in Lung Cancer Patients. Adv Exp Med Biol 2016;911:59-66.

37. Janelsins MC, Kesler SR, Ahles TA, et al. Prevalence, mechanisms and management of cancer-related cognitive impairment. Int Rev Psychiatry 2014;26:102-13.
38. Onyema OO, Decoster L, Njemini R, et al. Shifts in subsets of CD8+ T-cells as evidence of immunosenescence in patients with cancers affecting the lungs: an observational case-control study. BMC Cancer 2015;15:1016.

39. Alam I, Larbi A, Pawelec G. Nutritional status influences peripheral immune cell phenotypes in healthy men in rural Pakistan. Immun Ageing 2012;9:16.

40. Chandra RK. Nutrition and the immune system from birth to old age. Eur J Clin Nutr 2002;56:S73-S76.

41. Wang Z, Aguilar EG, Luna JI, et al. Paradoxical effects of obesity on $T$ cell function during tumor progression and PD-1 checkpoint blockade. Nat Med 2019;25:141-51.

42. Mavridis K, Michaelidou K. The obesity paradox in lung cancer: Is there a missing biological link? J Thorac Dis 2019;11:S363-S366.

43. Morel H, Raynard B, d'Arlhac M, et al. Prediagnosis weight loss, a stronger factor than BMI, to predict survival in patients with lung cancer. Lung Cancer 2018;126:55-63.

44. Ge T, Lin T, Yang J, et al. Nutritional status and related factors of patients with advanced lung cancer in northern China: A retrospective study. Cancer Manag Res 2019;11:2225-31.

45. Laurent M, Bastuji-Garin S, Plonquet A, et al. Interrelations of immunological parameters, nutrition, and healthcare-associated infections: Prospective study in elderly in-patients. Clin Nutr 2015;34:79-85.

46. Ahmad A, Gadgeel S. editors. Lung Cancer and Personalized Medicine. Advances in Experimental Medicine and Biology. 1st edition. Springer International Publishing, 2016;893:37-56.

47. Au B, Dale-McGrath S, Tierney MC. Sex differences in the prevalence and incidence of mild cognitive impairment: A meta-analysis. Ageing Res Rev 2017;35:176-99.

48. Schuurmans H, Steverink N, Lindenberg S, et al. Old or frail: what tells us more? J Gerontol A Biol Sci Med Sci 2004;59:M962-5.

Cite this article as: Soria-Comes T, Palomar-Abril V, Martín Ureste M, García Sánchez J, Marco Buades JE, Fernández Llavador MJ, López Gabaldón A, González Jurado M, Maestu Maiques IC. Cognitive impairment is related to a reduced count of T-lymphocytes in older patients diagnosed with non-small cell lung cancer (NSCLC). Transl Cancer Res 2020;9(11):68576866. doi: 10.21037/tcr-20-1997 